\title{
Exploratory Study of the BPM Tools Used by Romanian Industrial Service Companies to Increase Business Performance
}

\author{
Andreea Barbu, Petronela Cristina Simion, Mirona Ana Maria Popescu, \\ Iustina Cristina Costea Marcu, Mihai Valeriu Popescu \\ University Politehnica of Bucharest, Splaiul Independentei, 313, Bucharest, Romania
}

\begin{abstract}
With the development of technology and the phenomenon of digitalization, companies have begun to use IT solutions to suit their needs and competences, so that they can improve their organizational performance. One of the most used solutions by the firms for optimization, efficiency, dynamic adaptation and their integration with the technological trends is represented by Business Process Management solutions. Through this paper, it is desired to analyse the most used BPM tools used by the companies providing industrial services in Romania. In this regard, an exploratory study was carried out that presents the most important characteristics of the most popular BPM solutions from Romania. These solutions are compared according to a set of criteria, among which: operating system, main features, access mode, training ways, technical support, or integration with other systems. At the end of this paper, there are presented some suggestions regarding what an industrial service company should do to establish what kind of BPM solution is good for it.
\end{abstract}

Keywords - BPM, BPM tools, BPM solutions, business performance, business process performance

\section{Introduction}

Lately, the concept of performance has become more and more common among companies. They

DOI: 10.18421/TEM92-16

https://dx.doi.org/10.18421/TEM92-16

Corresponding author: Andreea Barbu, University Politehnica of Bucharest, Bucharest, Romania. Email: barbu.andreeab@yahoo.com

Received: 25 March 2020.

Revised: 16 April 2020.

Accepted: 26 April 2020.

Published: 27 May 2020.

(c) BY-NC-ND C 2020 Andreea Barbu et al; published by UIKTEN. This work is licensed under the Creative Commons Attribution-NonCommercial-NoDerivs 3.0 License.

The article is published with Open Access at www.temjournal.com want to find new ways to continuously improve their activity and results while keeping a record of the actions taken.

To improve their process performance, companies have started to use Business Process Management (BPM) solutions. Focusing on improving processes, the management of the company aims to increase the performance and the flexibility of the businesses, so that they can respond to the needs and the changes that have appeared on the market.

In this sense, over time, several BPM solutions have started to develop. Along with these have appeared various special software to meet the needs of companies in terms of improving process performance. However, the problem arises when the company management is not familiar with BPM technologies, does not know all the problems within its company, does not have an overview and does not discuss extensively with the developers of such software, choosing the solutions that are the cheapest or the most accessible.

Thus, the goal of this paper is to analyze some of the most known BPM tools that are used in the Romanian industrial services companies. The research methods used in this paper are: descriptive analysis, exploratory research, and comparative analysis. In order to find the best BPM solution for Romanian companies, the authors established a set of criteria based on which they compared the chosen BPM tools.

\section{Literature Review}

To remain competitive in the market and to increase their profitability, companies are increasingly focusing on improving their performance. Whether we are talking about the financial dimension, the one related to clients, internal processes, innovation and learning, companies want to bring changes in these areas so that the final result is a favorable one for the company [1].

One of the most analyzed aspects by the management of the companies but also by the 
researchers is the processes within the company. When it comes to improving process performance, the most successful companies choose to implement business process management [2].

According to Trætteberg and Krogstie [3], Business Process Management (BPM) is a way of understanding, documenting, modeling, analyzing, simulating, executing and continually changing the business process, using the company's resources in a way that contributes to improving the business performance. This is why, nowadays, BPM has started to be seen as a foundational element of running organizations [4].

BPM was always thought to be the solution by which businesses can become more efficient through automation [5]. BPM has been studied in the special literature both from the point of view of automation [6], as well as technological innovation [7], being considered one of the most important steps towards digitizing a company [5].

The need to adopt a BPM solution starts from the inefficient human resources. Both employees in management positions and those in executive positions can cause great losses at the process level, as they do not have a complete vision of the whole process and cannot keep up with all the activities carried out, with all the problems on flow, sometimes working chaotic and unsystematic [8]. The problems arising from this poor organization and preparation can lead to the appearance of errors on the flow, to exceeding the deadlines, to the disappearance of some data or even to the demotivation of the employees [9].

Among the advantages offered by Business Process Management (BPM) IT solutions are: flexibility of business processes, reduction of costs and risks, easy integration with other types of ERP or CRM systems, intuitive interface, easy to adopt by employees, automatic monitoring of user tasks, alerting the user when a new task appears, counting the time required to solve each task. Also, the BPM solutions help to standardize and automate the operational and financial processes within the company, identifying and eliminating redundant activities, providing the various reports needed for the activities carried out, real-time visualization of the work team's activities [10].

Taking into account the fact that lately more and more BPM solutions have started to appear, the problem faced by the management of the company is related to what type of solution to choose. In order to make such a choice, the management of the company should first have a good understanding of the company's situation, problems, successes, needs, and competencies, and then determine exactly what they want to improve. Only then, those in leadership positions should analyze the portfolio of existing
BPM solutions and based on the needs and objectives set, as well as the benefits offered by each solution, to make the best decision to improve organizational performance.

For this paper, the authors' goals were to get answers to the following questions:

- Q1. Which are the most used BPM tools used in Romanian industrial services companies?

- Q2. Which are the main features of the BPM tools used in Romanian industrial services companies?

- Q3. Which are the main criteria that are considered when we analyze a BPM tool?

- Q4. Taking into account the identified criteria, is there an appropriate BPM tool that can be used in Romanian industrial service companies to improve the business performance?

By using this exploratory research, it was conducted a comparative study focusing on some BPM tools that are used in the Romanian industrial services companies. Thus, the main objectives of this paper are:

- O1: Presenting the most important characteristics of the following BPMN tools: CPM-Cleaning Process Management, esFields, B-Logic Business Process Management, AuraPortal BPMS, JobRouter, Simple BPM, Automation Flow Robot, Contentum, ENOVIA 3DExperience.

- O2: Comparison of the chosen BPM tools from the point of view of: the license type, the operating system, the access from mobile devices, the main features, the language in which the application is available, the access mode, training ways, technical support, and integration with other systems.

- O3: Making suggestions on the direction that the BPM software should follow based on the results of this study.

\section{Methodology}

To achieve the proposed objectives, some research methods were used:

- Descriptive analysis

- Exploratory research

- Comparative analysis

For describing or comparing the BPM tools, the following criteria were taken into consideration: license type, operating system, access from mobile devices, main features, the language in which the application is available, access mode, training ways, technical support, and integration with other systems [11]. These criteria were chosen based on the research of the official pages of the software chosen 
to be analyzed, based on their searches performed on various software sites in Romania, these being the main features they identified and considered to be relevant to best describe a BPM tool.

\section{Findings}

To achieve the proposed goals, the authors have searched on several specialized sites that offer computer solutions for the company, analyzing the situation of the BPM type portfolio.

Analyzing the number of reviews offered by the users, the authors chose the most popular BPM solutions used by the Romanian companies: CPMCleaning Process Management, esFields, B-Logic Business Process Management, AuraPortal BPMS, JobRouter, Simple BPM, Automation Flow Robot, Contentum, and ENOVIA 3DExperience.

For better visualization of the data in the table, companies received codes from A to I as can be seen in Table 1.

Table 1. BPM tools codes

\begin{tabular}{|l|c|}
\hline BPM tools & Code \\
\hline CPM-Cleaning Process Management; & $\mathrm{A}$ \\
\hline esFields & $\mathrm{B}$ \\
\hline Logic Business Process Management & $\mathrm{C}$ \\
\hline AuraPortal BPMS & $\mathrm{D}$ \\
\hline JobRouter & $\mathrm{E}$ \\
\hline Simple BPM & $\mathrm{F}$ \\
\hline Automation Flow Robot & $\mathrm{G}$ \\
\hline Contentum & $\mathrm{H}$ \\
\hline ENOVIA 3DExperience & $\mathrm{I}$ \\
\hline
\end{tabular}

The first step in choosing the best BPM-type solutions in Romania is the brief presentation of these solutions, their characteristic information being taken from both the analyzed sites and the official states of BPM solutions.

\section{CPM-Cleaning Process Management (A)}

CPM-Cleaning Process Management is a BPM tool that is especially used in a network of chemical cleaners but with applicability in many areas where workflow tracking is required. It integrates the input or output data with those obtained from the scanners from each place of processing of textiles/leather (washing, ironing, sewing) obtaining both reports on when and who they performed various operations, as well as information necessary for the allocation of resources for the next day, exactly based on real needs. This tool has a lot of advantages both for companies and clients. For example, customers are informed about the status of the products they have in one of the chain stores much easier, while companies can obtain different types of reports about things like: products that are being processed or finalized, who and when one of the operations to which each product is subjected was performed; which is the efficiency of each employee or how to use efficiently both human and material resources. Other information about this tool can be found in Tables 2-10.

\section{EsFields (B)}

EsFields is a BPM tool that ensures the collection of information from the field, stored on mobile devices and transmitted online on the central server. Data collection is done based on configurable forms, which allows the retrieval and transfer of any type of information in various forms and structures. One of the most important advantages for the company is the transparent view of all the way down to the field data level, as well as providing field agents with easy access to central information and data, offering an automated alternative to repetitive tasks performed by field teams and providing managers with a better overview of their teams' activity, in real-time. Tables 1-9 contain more information about this tool.

\section{B-Logic Business Process Management (C)}

B-Logic Business Process Management is another BPM tool focusing on the facilitation of the implementation of quality standards. By using this kind of tool, companies can reduce costs, ensure clearer tasks, streamline business processes, optimize reaction time by using different types of alerts for delays. More information about this tool can be found in Tables 2-10.

\section{AuraPortal (D)}

AuraPortal is another BPM tool that is used in a lot of companies, and also in industrial services. Through this tool, companies can easily design and execute operating processes, without additional programming. The firms that are using AuraPortal are happy with this software because it is compatible with a lot of existing systems like Enterprise Resource Planning or Customer Relationship Management. Most of the characteristics of this tool are listed in Tables 2-10.

\section{JobRouter (E)}

JobRouter is a platform used by companies to digitize and automate various types of business processes. It is used both in production and in schools, governments, construction, accounting, human resources, operations and procurement. More information about this tool can be found in Tables 210. 


\section{Simple BPM (F)}

Simple BPM is a business process management application, which allows the modeling of the organization processes, flow execution, and document management. The main functionalities of the application refer to the improvement of the internal communication, creation of forms, execution of the processes, graphic modeling, automatic notifications, publication of content. Other significant information can be found in Tables 2-10.

\section{Automation Flow Robot (G)}

Automation Flow Robot is a BPM tool that ensures the automation of the business process for both small businesses and large or very large companies. Companies can use this tool to automate the routine tasks that are performed by employees, this kind of solution giving them more time for other tasks that require human interaction. This solution is preferred by many companies because is a cheap tool and it has an intuitive interface. Other important information about this BPM tool can be observed in Tables 2-10.

\section{Contentum (H)}

Contentum is a Business Process Management tool that drives digital transformation and allows shifting from job instructions to automated business processes and performance monitoring. It uses Business Process Model and Notation (BPMN) diagrams to control and monitor the execution of the real-life business processes, also being used to create flexible and adaptive BPM applications for the company. More information about this tool can be found in Tables 2-10.

\section{ENOVIA 3DExperience (I)}

ENOVIA 3DExperience is used by companies to help them in different domains, such as development and production, sales, maintenance and even withdrawal from the market. ENOVIA offers preconfigured "best-practice" methods for change management, which can be optionally adapted to the specific needs of the company. It can help the company to compare the various versions of existing processes over time, to communicate more efficiently internally, to import various historical data, to perform different types of diagrams and to simulate certain processes. More information about this tool can be found in Tables 2-10.

The next step was to conduct a comparative analysis of the BPM tools. The results of this analysis can be seen in Tables 2-10, where the analysis was realized based on the following criteria: the license type, the operating system, the access from mobile devices, the main features, the language in which the application is available, the access mode, training ways, technical support, and integration with other systems.

Table 2. License type

\begin{tabular}{|l|c|c|c|c|c|c|c|c|c|}
\hline License type & A & B & C & D & E & F & G & H & I \\
\hline SaaS & $\checkmark$ & $\checkmark$ & $\checkmark$ & $\checkmark$ & $\checkmark$ & $\checkmark$ & $\checkmark$ & $\checkmark$ & $\checkmark$ \\
\hline On-premises & $\checkmark$ & & & & $\checkmark$ & & $\checkmark$ & $\checkmark$ & $\checkmark$ \\
\hline
\end{tabular}

All of the analysed BPM tools have a SaaS license type, while only half of them have a license onpremises (Table 2.).

Table 3. Operating System

\begin{tabular}{|l|c|c|c|c|c|c|c|c|c|}
\hline Operating System & A & B & C & D & E & F & G & H & I \\
\hline Windows & $\checkmark$ & $\checkmark$ & $\checkmark$ & $\checkmark$ & $\checkmark$ & $\checkmark$ & $\checkmark$ & $\checkmark$ & $\checkmark$ \\
\hline Ubuntu & $\checkmark$ & & $\checkmark$ & $\checkmark$ & & $\checkmark$ & $\checkmark$ & $\checkmark$ & \\
\hline MacOS & $\checkmark$ & & $\checkmark$ & $\checkmark$ & & $\checkmark$ & $\checkmark$ & $\checkmark$ & \\
\hline CentOS & $\checkmark$ & & $\checkmark$ & $\checkmark$ & & $\checkmark$ & $\checkmark$ & $\checkmark$ & \\
\hline Redhat & $\checkmark$ & & $\checkmark$ & $\checkmark$ & & $\checkmark$ & $\checkmark$ & $\checkmark$ & \\
\hline
\end{tabular}

All of the analysed BPM tools work on windows operating system. Besides EsFields, JobRouter and Enovia 3DExperience, the rest of the BPM tools also works on Ubuntu, MacOS, CentOS or Redhat operating systems (Table 3.).

Table 4. Access from mobile devices

\begin{tabular}{|l|c|c|c|c|c|c|c|c|c|}
\hline \multicolumn{1}{|c|}{$\begin{array}{c}\text { Access from mobile } \\
\text { devices }\end{array}$} & A & B & C & D & E & F & G & H & I \\
\hline No & & & & & & & $\checkmark$ & & \\
\hline Via browser & $\checkmark$ & $\checkmark$ & $\checkmark$ & $\checkmark$ & $\checkmark$ & $\checkmark$ & $\checkmark$ & $\checkmark$ & $\checkmark$ \\
\hline $\begin{array}{l}\text { Via dedicated application } \\
\text { for iOS }\end{array}$ & $\checkmark$ & & & $\checkmark$ & & & & \\
\hline $\begin{array}{l}\text { Via dedicated application } \\
\text { for Android }\end{array}$ & $\checkmark$ & & & $\checkmark$ & & & & \\
\hline $\begin{array}{l}\text { Through dedicated } \\
\text { application for Windows } \\
\text { Mobile }\end{array}$ & $\checkmark$ & & & $\checkmark$ & & & & \\
\hline
\end{tabular}

Automation Flow Robot is the only tool that is not accessible from mobile devices. Only esFields and JobRouter can be accessed via dedicated applications for iOS, Android or Windows Mobile, the rest of them being accessed via a browser (Table 4.).

Table 5. Language

\begin{tabular}{|l|c|c|c|c|c|c|c|c|c|}
\hline Language & A & B & C & D & E & F & G & H & I \\
\hline Romanian & $\checkmark$ & $\checkmark$ & $\checkmark$ & $\checkmark$ & $\checkmark$ & $\checkmark$ & & $\checkmark$ & \\
\hline English & & $\checkmark$ & & $\checkmark$ & $\checkmark$ & $\checkmark$ & $\checkmark$ & $\checkmark$ & $\checkmark$ \\
\hline French & & $\checkmark$ & & $\checkmark$ & $\checkmark$ & $\checkmark$ & & $\checkmark$ & $\checkmark$ \\
\hline German & & $\checkmark$ & & $\checkmark$ & $\checkmark$ & $\checkmark$ & & $\checkmark$ & $\checkmark$ \\
\hline
\end{tabular}

It is interesting to analyze the language options available for the operation of various BPM solutions. As can be seen in Table 5., most of the tools can be operated in the Romanian language, while apart from CPM-Cleaning Process Management, B-Logic Business Process Management, the rest of the BPM 
tools can be operated in English, French and also German. Automation Flow Robot Automation is the only analysed tool that is available only in the English version.

Most of the BPM solutions need to be installed on the computer or server, half of them needing internet access to operate. Only 3 of them (esFields, Contentum, and CPM) can be installed on mobile or can work via the cloud, SaaS or web (Table 6.).

Table 6. Access mode

\begin{tabular}{|l|c|c|c|c|c|c|c|c|c|}
\hline Access mode & A & B & C & D & E & F & G & H & I \\
\hline $\begin{array}{l}\text { Access through the } \\
\text { company network }\end{array}$ & $\checkmark$ & & & & & & $\checkmark$ & & $\checkmark$ \\
\hline Internet access & $\checkmark$ & & $\checkmark$ & $\checkmark$ & & $\checkmark$ & & & \\
\hline $\begin{array}{l}\text { Installation on } \\
\text { computer/ server }\end{array}$ & $\checkmark$ & $\checkmark$ & & & $\checkmark$ & & $\checkmark$ & $\checkmark$ & \\
\hline $\begin{array}{l}\text { Install on mobile (iOS } \\
\text { and native Android) }\end{array}$ & $\checkmark$ & $\checkmark$ & & & & & & $\checkmark$ & \\
\hline Cloud, SaaS, Web & $\checkmark$ & $\checkmark$ & & & & & & $\checkmark$ & \\
\hline
\end{tabular}

The main features of the BPM tools are: Automatic notifications, Graphic modeling, EPC diagram, Swim lane diagram, Versioning processes, Process simulation, Content publishing, Versioning processes, Comparator on trial versions, Execution of processes, Forms creation, Internal communication, import historical data, and Activity logging. Only AuraPortal BPMS, JobRouter, Simple BPM, Automation Flow Robot, Contentum, and ENOVIA 3DExperience have all of these features. CPMCleaning Process Management and esFields have similar features, at the same time being the tools with the least features (Table 7.).

Table 7. Main features

\begin{tabular}{|l|c|c|c|c|c|c|c|c|c|}
\hline Main features & A & B & C & D & E & F & G & H & I \\
\hline Automatic notifications & $\checkmark$ & $\checkmark$ & $\checkmark$ & $\checkmark$ & $\checkmark$ & $\checkmark$ & $\checkmark$ & $\checkmark$ & $\checkmark$ \\
\hline Graphic modeling & & & $\checkmark$ & $\checkmark$ & $\checkmark$ & $\checkmark$ & $\checkmark$ & $\checkmark$ & $\checkmark$ \\
\hline EPC diagram & & & $\checkmark$ & & $\checkmark$ & $\checkmark$ & $\checkmark$ & $\checkmark$ & $\checkmark$ \\
\hline Swim lane diagram & & & $\checkmark$ & $\checkmark$ & $\checkmark$ & $\checkmark$ & $\checkmark$ & $\checkmark$ & $\checkmark$ \\
\hline Versioning processes & $\checkmark$ & $\checkmark$ & $\checkmark$ & $\checkmark$ & $\checkmark$ & $\checkmark$ & $\checkmark$ & $\checkmark$ & $\checkmark$ \\
\hline Process simulation & & & $\checkmark$ & $\checkmark$ & $\checkmark$ & $\checkmark$ & $\checkmark$ & $\checkmark$ & $\checkmark$ \\
\hline Content publishing & $\checkmark$ & $\checkmark$ & $\checkmark$ & $\checkmark$ & $\checkmark$ & $\checkmark$ & $\checkmark$ & $\checkmark$ & $\checkmark$ \\
\hline Versioning processes & $\checkmark$ & $\checkmark$ & $\checkmark$ & $\checkmark$ & $\checkmark$ & $\checkmark$ & $\checkmark$ & $\checkmark$ & $\checkmark$ \\
\hline Comparator on trial versions & & & $\checkmark$ & $\checkmark$ & $\checkmark$ & $\checkmark$ & $\checkmark$ & $\checkmark$ & $\checkmark$ \\
\hline Execution of processes & & & $\checkmark$ & $\checkmark$ & $\checkmark$ & $\checkmark$ & $\checkmark$ & $\checkmark$ & $\checkmark$ \\
\hline Forms creation & $\checkmark$ & $\checkmark$ & $\checkmark$ & $\checkmark$ & $\checkmark$ & $\checkmark$ & $\checkmark$ & $\checkmark$ & $\checkmark$ \\
\hline Internal communication & $\checkmark$ & $\checkmark$ & & $\checkmark$ & $\checkmark$ & $\checkmark$ & $\checkmark$ & $\checkmark$ & $\checkmark$ \\
\hline Import historical data & $\checkmark$ & $\checkmark$ & & $\checkmark$ & $\checkmark$ & $\checkmark$ & $\checkmark$ & $\checkmark$ & $\checkmark$ \\
\hline Activity logging & $\checkmark$ & $\checkmark$ & $\checkmark$ & $\checkmark$ & $\checkmark$ & $\checkmark$ & $\checkmark$ & $\checkmark$ \\
\hline
\end{tabular}

Implementing a BPM solution is a wise investment that brings many benefits, but when opting for such software, it must be taken into account the transition period from the old work system to the new work system. Thus, the training and support part is a very important thing that companies should pay attention to when choosing such a solution.
In terms of training solutions offered by enterprises, we discovered that we have courses, special documentation or webinars (Table 8.). Courses and documentations are the most common ways of training most companies providing both types of variants (esFields, B-Logic Business Process Management, AuraPortal BPMS, JobRouter, Simple BPM, ENOVIA 3DExperience). CPM-Cleaning Process Management only provides training solutions via courses, while Automation Flow Robot provides companies with special documentation for using the software. B-Logic Business Process Management, AuraPortal BPMS, Simple BPM, and ENOVIA 3DExperience pay more attention to training solutions, offering to clients training both through courses, as well as through special documentation or webinars, being the best software choices in this regard. Unfortunately, at this chapter Contentum is the worst choice, having no training solution to offer to customers.

Table 8. Training ways

\begin{tabular}{|l|c|c|c|c|c|c|c|c|c|}
\hline Training ways & A & B & C & D & E & F & G & H & I \\
\hline Course & $\checkmark$ & $\checkmark$ & $\checkmark$ & $\checkmark$ & $\checkmark$ & $\checkmark$ & & & $\checkmark$ \\
\hline Through documentation & & $\checkmark$ & $\checkmark$ & $\checkmark$ & $\checkmark$ & $\checkmark$ & $\checkmark$ & & $\checkmark$ \\
\hline Webinar & & & $\checkmark$ & $\checkmark$ & & $\checkmark$ & & & $\checkmark$ \\
\hline
\end{tabular}

Taking into account the technical support, Contentum is the only BPM tool that offers technical support permanently (24/7), while the others except for Enovia, offer technical support only during the working hours. ENOVIA 3DExperience is the only BPM tool that does not provide technical support. This can be explained by the fact that the company focuses more on training solutions, offering to customers the possibility to learn how to use their software via courses, documentation or webinars (Table 9.).

\section{Table 9. Technical support}

\begin{tabular}{|l|c|c|c|c|c|c|c|c|c|}
\hline Technical support & A & B & C & D & E & F & G & H & I \\
\hline During working hours & $\checkmark$ & $\checkmark$ & $\checkmark$ & $\checkmark$ & $\checkmark$ & $\checkmark$ & $\checkmark$ & & \\
\hline Permanent (24/7) & & & & & & & & $\checkmark$ & \\
\hline
\end{tabular}

The last chapter that we analyzed is the integration with other systems. We discovered that esFields, JobRouter, Automation Flow Robot, and ENOVIA 3DExperience can be integrated with other systems by standards, Simple BPM and Contentum can be integrated with other systems only by development upon request and with additional costs, while BLogic Business Process Management and AuraPortal BPMS cannot be integrated with other systems. Unfortunately, we could not find information about this dimension about CPM-Cleaning Process Management (Table 10.). 
Table 10. Integration with other systems

\begin{tabular}{|l|c|c|c|c|c|c|c|c|c|}
\hline Integration with other systems & A & B & C & D & E & F & G & H & I \\
\hline Yes, by standards & & $\checkmark$ & & & $\checkmark$ & $\checkmark$ & & $\checkmark$ \\
\hline Yes, by development upon request & & & & & & $\checkmark$ & & & \\
\hline No & & & $\checkmark$ & $\checkmark$ & & & & \\
\hline
\end{tabular}

\section{Conclusion}

All the presented BPM tools were analysed based on the following criteria: license type, operating system, access from mobile devices, main features, the language in which the application is available, access mode, training ways, technical support, and integration with other systems. Taking into account all these dimensions, it can be said that few solutions have a complex contribution to the good development of the company. Simple BPM, Aura Portal BPMS, and Contentum are the best 3 solutions that are recommended by the authors for a service company that wants to start its improvement performance journey. All of these tools are offering complex and complete solutions characteristics to the BPM dimension, complex training solutions, the software being available in 4 languages.

Even if a company should not consider the tools mentioned above, the management of the company should first analyse the problems and needs existing in the firm. Only after they know the complete and real situation of the company, they must review the goals of the company to establish what they need to improve at the processes, employees, organizational culture, customer satisfaction or innovation level. If the management of the company is not very capable and has no specialized knowledge to make the best decisions taking into account all the departments and problems of the company, it should call on a company that offers technical consulting. Together with them, it should establish the main functionalities that a BPM solution should offer, and by reviewing the company's capabilities, resources and budgets, contact various companies that offer such BPM solutions to make the decision better in order to improve the organizational performance.

However, the results of this research must be interpreted with care, the present study also has certain limitations. First, the selection of BPM solutions was based on the number of public reviews existing on specialized sites in Romania. The results can also be influenced by the fact that not all companies that use these services offer feedback on their experience with these tools.

Secondly, there may be other criteria that can be used for the analysis of companies, the authors analyzing the BPM solutions according to the types of public data found on the official websites of the BPM solutions or on the sites where they were available for purchase. Thirdly, it is possible that, in the case of certain criteria, certain characteristic data may be missing in certain companies as they are not made public, which ultimately affects the position of the company related to the situation of the others analyzed. Also, there are limitations regarding the lack of price information for each solution analyzed, as the price is established with each company, depending on the needs and the needs of the client, the changes that need to be made, but also the type and the duration of the desired partnership. Thus, it is hoped that in the future a discussion will be held with each representative of these BPM solutions to present a complete offer of these tools, which will be based on discussions, needs and exact scenarios, and not only on the main features of the solutions that are available online.

\section{Acknowledgement}

This work has been funded by the European Social Fund from the Sectoral Operational Programme Human Capital 2014-2020, through the Financial Agreement with the title "Scholarships for entrepreneurial education among doctoral students and postdoctoral researchers (Be Antreprenor!)", Contract no. 51680/09.07.2019 - SMIS code: 124539.

\section{References}

[1]. Kaplan, R.S., \& Norton, D.P. (1996). The Balanced Scorecard: Translating Strategy into action, Boston: Harvard Business School Press

[2]. Miers, D. (2005). Bpm: driving business performance. BP Trends, 5(1).

[3]. Trætteberg, H., \& Krogstie, J. (2008, November). Enhancing the usability of bpm-solutions by combining process and user-interface modelling. In IFIP Working Conference on The Practice of Enterprise Modeling (pp. 86-97). Springer, Berlin, Heidelberg.

[4]. Hull, R., \& Nezhad, H. R. M. (2016, September). Rethinking BPM in a cognitive world: Transforming how we learn and perform business processes. In International Conference on Business Process Management (pp. 3-19). Springer, Cham.

[5]. Kemsley, S. (2015). Emerging technologies in BPM. In BPM-Driving Innovation in a Digital World (pp. 51-58). Springer, Cham.

[6]. Aysolmaz, B., İren, D., \& Demirörs, O. (2013). An effort prediction model based on BPM measures for process automation. In Enterprise, Business-Process and Information Systems Modeling (pp. 154-167). Springer, Berlin, Heidelberg.

[7 Schmiedel, T., \& vom Brocke, J. (2015). Business process management: Potentials and challenges of driving innovation. In BPM-Driving Innovation in a Digital World (pp. 3-15). Springer, Cham.

[8]. Oliveira, C. A., Lima, R. M., \& Reijers, H. A. (2015). Implementing a Digital Strategy through Business Process Management. In BPM-Driving Innovation in a Digital World (pp. 231-245). Springer, Cham.

[9]. Kissflow. (2019). A Full Overview of Business Process Management (BPM). Retrieved from: https://kissflow.com/bpm/business-processmanagement-overview/, [accessed: 25 January 2020].

[10]. Convex. (2019). Business Process Management, Retrieved from:

https://convex-network.ro/softwaresolutions/business-process-management/, [retrieved: 25 January 2020]. 